\title{
Role of Transcranial Direct Current Stimulation in the Management of Post-Stroke Depression
}

\author{
T. Alloush1, E. Fayez², I. Abd-Allah Al-Azab², M. Bouls², M. Hamdy ${ }^{1}$ \\ ${ }^{1}$ Neurology and Psychiatry Department, Faculty of Medicine, Ain Shams University, Cairo, Egypt \\ ${ }^{2}$ Physical Therapy Department for Neuromuscular Disorder and Its Surgery, Faculty of Physical Therapy, Cairo University, \\ Cairo, Egypt \\ Email: mohamedhamdy_neuro2007@yahoo.com
}

How to cite this paper: Alloush, T., Fayez, E., Al-Azab, I.A.-A., Bouls, M. and Hamdy, M. (2020) Role of Transcranial Direct Current Stimulation in the Management of PostStroke Depression. Neuroscience \& Medicine, 11, 1-11.

https://doi.org/10.4236/nm.2020.111001

Received: December 8, 2019

Accepted: January 10, 2020

Published: January 13, 2020

Copyright (c) 2020 by author(s) and Scientific Research Publishing Inc. This work is licensed under the Creative Commons Attribution-NonCommercial International License (CC BY-NC 4.0).

http://creativecommons.org/licenses/by-nc/4.0/

\section{Open Access}

\begin{abstract}
Study Objectives: Stroke is a major neurological disease significantly threatening the human health and life with a high morbidity, disability, and mortality. Post-stroke depression (PSD) is one of the common complications of stroke. PSD has been a major factor hindering the recovery of neurological functions and daily activities in stroke patients and is closely related to the social avoidance and increased mortality of stroke patients. Although antidepressant drug treatment has improved during the last decades, symptoms in about $20 \%$ of the patients are not in remission two years after initiation of pharmacological intervention. Nowadays, non-invasive brain stimulation; techniques; transcranial direct current stimulation (tCDS) has gained an important interest in the treatment of many neuropsychiatric disorders which might be of some help in treatment of PSD. The goal of the current study is to evaluate the beneficial short term role of tDCS on post-stroke depression. Study Design: This was a randomized double blind placebo-controlled clinical trial included forty hemiparetic patients with post-stroke depression from outpatient clinic of Faculty of Physical Therapy, Cairo University, in the period between June 2018 to June 2019. All patients diagnosed as having a PSD according to the Diagnostic and Statistical Manual of Mental Disorders (DSM-5). Depression was evaluated by Hamilton Depression Rating Scale (HAM-D) pre and post treatment and quality of life was evaluated by the Stroke Specific Quality Of Life scale (SS-QOL). Patients were assigned randomly into two groups: the study group A and the control group B. Both groups received antidepressant medication in addition to physical therapy program. Group A received tCDS for 30 minutes, three times per week for one month, while the group B received sham transcranial direct current stimulation. Results: Active tDCS was significantly superior to sham with significant improvement in depression and Stroke Specific Quality Of Life in treated group in com-
\end{abstract}


parison to group $\mathrm{B}, \mathrm{p}=0.000$. Conclusion: tDCS was effective for poststroke depression and might be a favorable option for treating post-stroke patients.

\section{Keywords}

Post-Stroke Depression, Transcranial Direct Current Stimulation, Diagnostic and Statistical Manual of Mental Disorders

\section{Introduction}

Stroke is the leading risk factor for severe physical disability and cognitive impairment [1]. Even if a significant number of stroke victims achieve at least some spontaneous recovery, it remains one of the main causes of permanent disability. One of serious neuropsychiatric stroke complication, that negatively affects the therapeutic outcome, is post-stroke depression (PSD). The prevalence of PSD is $25 \%$ to $79 \%$, depending on the setting, assessment tool, and time post-stroke [2]. In Egypt, the prevalence of PSD in recent study was 60.78\% [3]. Patients with post-stroke depression (PSD) show far less recovery from functional impairments compared with non-depressed patients with stroke.

Currently, pharmacotherapy is the most commonly prescribed and effective treatment option for major depression of all etiologies, despite the fact that approximately $30 \%$ of depressed individuals have treatment-resistant depression [4]. For individuals with PSD pharmacotherapy may be associated with increased risk of mortality and subsequent stroke. Therefore, these individuals may require novel alternative or adjunctive treatments to optimally manage the condition. Non-invasive brain stimulation (NIBS) techniques; trans Magnetic Stimulation (TMS) and transcranial direct current stimulation (tCDS) are also an alternative option, which are a non-expensive, non-invasive and relatively painless treatment [5].

Neuronal reorganization and plasticity that follow stroke may be beneficial or maladaptive and NIBS, like tDCS, can be used to monitor and modulate this mechanism, facilitating or disrupting the neuronal activity, creating temporary or long-lasting desirable brain changes [6]. tDCS produces a subsensory level of electrical stimulation which alters neuronal resting membrane potentials to facilitate (anodal) or inhibit (cathodal) neuronal firing rates [7]. tDCS can locally reduce gamma-aminobutyric acid (GABA) neurotransmission [8]. Thus tDCS may interfere with functional connectivity, synchronization, and oscillatory activities in various cortical and subcortical networks [9]. Also, tDCS might elicit changes in non-neuronal tissues in the brain; almost all tissues and cells, including endothelial cells, lymphocytes, or glial cells [10]. tDCS relies on the application of a weak direct current of $1-2 \mathrm{~mA}$ directly to the scalp through electrodes to induce regional changes in cortical excitability that can last up to a few hours after stimulation [7]. 
Left anterior lesions are associated with an increased risk of depression after stroke; specifically, the left dorsolateral prefrontal cortex (DLPFC) damage is correlated with more severe depression symptoms [11]. To achieve antidepressant effects, anodal tDCS is delivered over the left DLPFC (believed to be hypoactive in depression) to increase cortical excitability. Cathodal tDCS is delivered over the right DLPFC (believed to be for hyperactive in depression to decrease cortical excitability) [12].

Fregni et al. (2006) reported a positive result on the efficacy of five sessions of anodal tDCS applied over the left DLPFC in ten patients with major depressive disorder [13]. Rigonatti et al. (2008) compared the effect of fluoxetine and ten tDCS sessions in 42 depressed patients, and noted a similar improvement in depressive symptoms following brain stimulation and pharmacological treatment, with an earlier antidepressant action in the tDCS group [14]. Regarding post-stroke depression, Valiengo et al. (2017) studied the effects after active tDCS versus sham stimulation in 45 patients and reported a higher response rate with active stimulation (37.5\% and $20.8 \%$, respectively) and higher remission rates $(4.1 \%$ and $0 \%$, respectively) [15]. Several characteristics such as; noninvasiveness, absence of pharmacokinetics interactions, safety, tolerability, and low-cost make tDCS an interesting tool to be used in the treatment of psychiatric disorders [16].

The aim of this study was to evaluate the effectiveness of tDCS in treatment of post-stroke depression.

\section{Subject and Methods}

\subsection{Study Subject}

This was an analytical observational study that was conducted on 40 participants from the outpatient clinics of Faculty of Physical Therapy, Cairo University in the period from June 2018 to June 2019, after the patients signed an informed consent. The inclusion criteria were patients with post-stroke depression. Stroke was defined according to the definition of the World Health Organization as the rapid onset of a new persistent neurological deficit attributable to an obstruction in cerebral blood flow with no apparent non-vascular cause [17]. The diagnosis of post-stroke depression was made based on the Diagnostic and Statistical manual Mental Disorder (DSM-5) Criteria, with age 45 years old and above [18]. Exclusion criteria were patients with language defects that may impair patient's cooperation, patients with vascular dementia (MMSE < 24) [19], patients with secondary medical comorbidity that could affect outcome of the study as stroke, renal failure and liver cell failure and the presence of contraindication for rTMS as history of seizures, presence of metallic devices; pace maker and cochlear implants, head injuries or neurosurgical interventions and pregnancy [20].

The patients were randomly assigned to either an actively treated group A (n 20) or a sham-treated group B (n 20). Patients were maintained on their medications without any modifications and conventional physical therapy. The tDCS protocol involved generating a direct current using FDA approved batteries 
(Phoresor $^{\circledR}$ PM 850 (Phoresor $^{\circledR}$ II Auto Model No. PM 850, IOMED, Inc., SaltLake City, USA). According to the International 10 - 20 system, the anode was wrapped in straps and attached to the left DLPFC, while the cathode was attached in the same manner to the right DLPFC. The group A patients received tDCS applied at $2 \mathrm{~mA} 12$ times over the course of four weeks (three times a week), for 30 minutes during each session based on the stability study by Bueno et al. (2011) [21]. In group B, the anode and cathode positions were the same as in the group A; however, the stimulation was stopped 30 seconds after the application without letting the participants know until 30 minutes elapsed.

All subjects undergone a full clinical, neurological and psychiatric examination, radiological investigations including computed tomography and/or magnetic resonance imaging of the brain, the Hamilton depression (HAM-D) scale and the Stroke-Specific Quality of Life (SS-QOL) Scale [22] [23]. The SS-QOL scale is a self-report questionnaire consisting of 49 items in the 12 domains of energy, family roles, language, mobility, mood, personality, self-care, social roles, thinking, upper extremity function, vision, and work/productivity.

All subjects were subjected to baseline assessment before tDCS sessions and one month after trial completion with HAM-D and SS-QOL Scales. Experimental procedures were previously approved by the faculty of physical therapy Cairo University Institutional Review Board.

\subsection{Statistical Analysis}

All data collected were tabled and statistical analyzed by using the 'Statistical Package for Social Science (SPSS) version 23. The mean and standard deviation of all scores in the two groups were calculated using descriptive statistics. The difference between scores measured before and after treatment was determined using a paired t-test. The statistical significance level $(\alpha)$ was set at 0.05 .

\section{Results}

\subsection{General Demographic Features of Both Groups (A and B)}

The mean values of age/years in group (A) and group (B) were (54.60 \pm 4.057 , and $56.35 \pm 3.87)$ respectively. The mean values of height of the patients in group (A) and group (B) were $(163.80 \pm 5.53$ and $163.50 \pm 4.41)$ respectively. The mean values of weight in group (A) and group (B) were (84.25 \pm 7.89 and $87.50 \pm 7.87)$ respectively. The mean values of Body Mass Index (BMI) $\mathrm{Kg} / \mathrm{m}^{2}$ in group (A) and group (B) were $(26.83 \pm 2.36,27.21 \pm 2.45)$ respectively, Table 1. There were no statistical significant difference as regards age, height, weight and mass index between both groups, $\mathrm{P}>0.05$. No side-effects occurred in the treated group (itching, tingling, headache, discomfort, fatigue and burning sensation on the application site).

\subsection{Clinical Features in Both Groups Pretreatment}

Also, there were no statistical significant difference as regards sex, paretic side, 
Table 1. General features of the patients in both groups.

\begin{tabular}{cccccc}
\hline & $\begin{array}{c}\text { Group (A) } \\
\text { (n 20) }\end{array}$ & $\begin{array}{c}\text { Group (B) } \\
(\mathrm{n} \mathrm{20})\end{array}$ & t-value & p value \\
\cline { 2 - 3 } & Mean $\pm \mathrm{SD}$ & Mean $\pm \mathrm{SD}$ & & \\
\hline 1-Age (years) & $54.60 \pm 4.057$ & $56.35 \pm 3.87$ & 1.36 & 0.189 \\
2-Height $(\mathrm{Cm})$. & $163.80 \pm 5.53$ & $163.50 \pm 4.41$ & 0.21 & 0.838 \\
3-Weight $(\mathrm{Kg})$. & $84.25 \pm 7.89$ & $87.50 \pm 7.87$ & & 1.83 & 0.083 \\
4-BMI/(Kg/m $)$ & $26.83 \pm 2.36$ & $27.21 \pm 2.45$ & & 0.17 & 0.833 \\
\hline
\end{tabular}

SD: standard deviation. $\mathrm{P}>0.05=$ Non-significant.

type of stroke and duration of illness between both groups. As the number of male/female in group (A) and group (B) were (15/5 and 16/4) respectively. The paretic side were 13 with left sided and 7 with right sided in both groups. The cause of stroke was cerebral infarction in group (A) and group (B) were (12 and 13) respectively and cerebral hemorrhage in group (A) and group (B) were (8 and 7) respectively. The duration of illness (months) in group (A) and group (B) were $(14.5 \pm 5.3$ and $14.6 \pm 5.1)$ respectively, Table 2 .

\subsection{Comparison of the Mean Values of Hamilton Depression (HAM-D) Scale and Stroke-Specific Quality of Life (SS-QOL) Scale in Both Groups Pretreatment}

There were no statistical significant difference as regards HAM-D scale and SS-QOL Scale between both groups pretreatment, $\mathrm{P}>0.05$. As, the mean value for HAM-D scale for groups A and B pretreatment were $15.30 \pm 3.82$ and 15.45 \pm 2.70 respectively. $\mathrm{t}$-value was 0.16 and $\mathrm{P}=0.878$. The mean value for SS-QOL Scale pretreatment for groups and B were $123.50 \pm 18.98$ and $121.05 \pm 16.21$ respectively. $\mathrm{t}$-value was 0.52 and $\mathrm{P}=0.607$, Table 3 .

\subsection{Comparison of the Mean Values of HAM-D Scale and SS-QOL Scale in Both Groups Post Treatment}

There was a significant difference between both groups regarding HAM-D scale and SS-QOL Scale post treatment; $\mathrm{p} \leq 0.05$. As, the mean value for HAM-D scale for groups $A$ and B post treatment were $11.9 \pm 4.87$ and $15.25 \pm 3.32$ respectively. $\mathrm{t}$-value was 2.56 and $\mathrm{P}=0.019$. The mean value for SS-QOL Scale post treatment for groups A and B were $144.70 \pm 27.77$ and $124.05 \pm 18.44$ respectively. $t$ value was 2.71 and $\mathrm{P}=0.014$, Table 4 .

\subsection{Comparison of the Mean Values of HAM-D Scale in both Groups before and after Treatment}

There was a statistical significant difference for group (A) regarding HAM-D scale before and after treatment, $p=0.000$. As, the mean values of HAM-D scale in group (A) pretreatment was $15.3 \pm 3.82$ and post treatment it improved significantly to $11.9 \pm 4.87$ and t-value was 6.24 Table 5 . But, there was no statistical 
Table 2. The clinical features of both groups.

\begin{tabular}{cccccc}
\hline \multirow{2}{*}{ Categories } & \multicolumn{2}{c}{ Group (A) } & \multicolumn{2}{c}{ Group (B) } \\
\cline { 2 - 6 } & & $\mathrm{N}$ & $\%$ & $\mathrm{~N}$ & $\%$ \\
\hline \multirow{2}{*}{ 1-Gender } & Male & 15 & 75 & 16 & 80 \\
& Female & 5 & 25 & 4 & 20 \\
2-Paretic side & Left & 13 & 65 & 13 & 65 \\
& Right & 7 & 35 & 7 & 35 \\
3-Cause of stroke & Cerebral infarction & 12 & 60 & 13 & 65 \\
& Cerebral hemorrhage & 8 & 40 & 7 & 35
\end{tabular}

Table 3. Comparison of the mean values of the patients in both groups pretreatment.

\begin{tabular}{ccccc}
\hline & \multicolumn{3}{c}{ Pretreatment } \\
\cline { 2 - 4 } & Group (A) & Group (B) & t-value & p-value \\
\cline { 2 - 4 } & Mean \pm SD & Mean \pm SD & & 0.878 \\
1-HAM-D Scale & $15.30 \pm 3.82$ & $15.45 \pm 2.70$ & 0.16 & 0.607 \\
\hline
\end{tabular}

SD: standard deviation; $\mathrm{P}>0.05=$ Non-significant.

Table 4. Mean values of HAM-D scale, and SS-QOL Scale in both groups post treatment.

\begin{tabular}{ccccc}
\hline & \multicolumn{3}{c}{ Post treatment } \\
\cline { 2 - 4 } & Group (A) & Group (B) & t-value & p-value \\
\cline { 2 - 4 } & Mean \pm SD & Mean \pm SD & & $0.019^{*}$ \\
2-SS-QOL Scale & $11.9 \pm 4.87$ & $15.25 \pm 3.32$ & 2.56 & $0.014^{*}$ \\
\hline
\end{tabular}

SD: standard deviation; $\mathrm{P} \leq 0.05=$ significant $^{*}$.

Table 5. Comparison of the mean values of HAM-D scale in both groups before and after treatment.

\begin{tabular}{|c|c|c|c|c|}
\hline \multirow{3}{*}{ Descriptive results } & \multicolumn{4}{|c|}{ HAM-D scale } \\
\hline & \multicolumn{2}{|c|}{$\operatorname{Group}(A)$} & \multicolumn{2}{|c|}{ Group $(B)$} \\
\hline & Pretreatment & Post treatment & Pretreatment & Post treatment \\
\hline Mean \pm SD & $15.3 \pm 3.82$ & $11.9 \pm 4.87$ & $15.45 \pm 2.70$ & $15.25 \pm 3.32$ \\
\hline Median & 15.00 & 10.5 & 15.5 & 15 \\
\hline Minimum & 9 & 5 & 10 & 15 \\
\hline Maximum & 24 & 23 & 20 & 21 \\
\hline t-value & \multicolumn{2}{|c|}{6.24} & \multicolumn{2}{|c|}{0.44} \\
\hline $\begin{array}{c}\text { Statistical p value } \\
\text { post treatment }\end{array}$ & \multicolumn{2}{|c|}{$0.000^{*}$} & \multicolumn{2}{|c|}{0.66} \\
\hline
\end{tabular}

SD: standard deviation; $\mathrm{P} \leq 0.05=$ significant $^{*}$. 
significant difference for group (B) regarding HAM-D scale before and after treatment, $p=0.66$. As, the mean values of HAM-D scale in group (B) pretreatment was $15.45 \pm 2.70$ and post treatment it was $15.25 \pm 3.32$ and $t$-value was 0.44 .

\subsection{Comparison of the Mean Values of SS-QOL Scale in Both Groups before and after Treatment}

There was a statistical significant difference for group (A) regarding SS-QOL Scale before and after treatment, $p=0.000$. As, the mean values of SS-QOL Scale in group (A) pretreatment was $123.50 \pm 18.98$ and post treatment it improved significantly to $144.70 \pm 27.77$ and t-value was 5.33 (Table 6). But, there was no statistical significant difference for group (B) regarding SS-QOL Scale before and after treatment, $\mathrm{p}=0.66$. As, the mean values of SS-QOL Scale in group (B) pretreatment was $121.05 \pm 16.21$ and post treatment was $124.05 \pm 18.44$, $t$-value was 1.2 and $\mathrm{P}=0.243$.

\section{Discussion}

Post-stroke depression (PSD) is a common affective disorder that can develop after stroke. Patients with PSD show poorer functional and recovery outcomes than patients with stroke who do not suffer from depression with higher risk of suicide [24]. Pharmacological treatments have limited efficacy and important adverse effects. Noninvasive neurostimulatory and neuromodulatory techniques; TMS and tDCS are rapidly emerging as a therapeutic strategy in various psychiatric disorders [25].

The current study results revealed that tDCS intervention caused a significant decrease in depression assessed by HDS in the actively treated group (A). Similar findings were observed by Valiengo et al. (2016) who used tDCS to the DLPFC of 23 patients with post-stroke depression and aphasia and found that their depressive symptoms decreased after four weeks [26]. Also, Valiengo et al. (2017)

Table 6. Comparison of mean values of SS-QOL Scale in both groups before and after treatment.

\begin{tabular}{|c|c|c|c|c|}
\hline & \multicolumn{4}{|c|}{ SS-QOL Scale } \\
\hline & \multicolumn{2}{|c|}{ Group $(A)$} & \multicolumn{2}{|c|}{ Group (B) } \\
\hline & Pretreatment & Post treatment & Pre treatment & Post treatment \\
\hline Mean \pm SD & $123.50 \pm 18.98$ & $144.70 \pm 27.77$ & $121.05 \pm 16.21$ & $124.05 \pm 18.44$ \\
\hline Median & 15.00 & 10.5 & 15.5 & 15 \\
\hline Minimum & 97.00 & 99.00 & 98.00 & 95.00 \\
\hline Maximum & 159.00 & 185.00 & 157 & 157 \\
\hline $\mathrm{t}$-value & \multicolumn{2}{|c|}{5.33} & \multicolumn{2}{|c|}{1.21} \\
\hline $\begin{array}{l}\text { Statistical p value } \\
\text { post treatment }\end{array}$ & \multicolumn{2}{|c|}{$0.000^{*}$} & \multicolumn{2}{|c|}{0.243} \\
\hline
\end{tabular}

SD: standard deviation; $\mathrm{P}>0.05=$ Non-significant, $\mathrm{P} \leq 0.05=$ significant $^{*}$. 
found that active tDCS was significantly superior with higher response and remission rates in 48 antidepressant-free patients with post-stroke depression [15]. As, in depression there is prefrontal asymmetry with right prefrontal activity hyperactivity [27]. Thus the anode was positioned over the left DLPFC and the cathode over the right DLPFC. The anode stimulation is known to increase the excitability of cerebral cortex, while the cathode stimulation is known to suppress the excitability of the cerebral cortex [28]. It can be assumed that the improvement of depression was caused by tDCS might be due to the modulation of serotonergic and dopaminergic systems, which have traditionally been associated with the pathogenesis of affective disorders [25].

In addition to the improvement in depression symptoms, the current study found a significant increase in the SS-QOL scale of the actively treated group (A); improvement in behavior, cognition, functional mobility, language, negative affect, personality, quality of life, social relationships and upper extremity function . Similar findings was reported by Viana et al. (2014) who found significant improvement in the QOL as well as upper limb function in group of stroke patients received virtual reality therapy (VRT) as well as tDCS in comparison to the sham group [29]. Also, Elsner et al. (2017) suggested effectiveness of tDCS for arm rehabilitation after stroke in their network meta-analysis [30]. Since tDCS enhances neuroplasticity by modulating cortical activity resulting in sufficient cortical activity and ameliorates functional loss in stroke [31] [32].

In agreement with the results of current study Fregni et al. (2006) reported that repeated sessions of active tDCS do not result in cognitive impairment compared to placebo tDCS in patients with depression [33]. On the contrary, Fregni et al. (2006) reported an improvement in one aspect of cognitive function; working memory and this cognitive enhancement was not observed after sham tDCS and was not correlated with mood effects [33]. Also, Pisoni et al. (2018) found that anodal tDCS of the left DLPFC enhances cognitive performance in healthy subjects and such facilitation is supposed to be linked to the plastic changes at relevant cortical sites [34].

In the current study there were no side-effects in the treated group. Similar findings were reported by Herrera-Melendez et al. (2019), that tDCS is well tolerated, comparably easy to handle and cheap to use [25].

\section{Limitations and Strengths}

This study has two limitations: 1 ) the results are difficult to generalize due to the small sample size, and 2) other factors influencing QOL have not been investigated.

The strength of this study includes; to our knowledge, this is one of few human studies to explore the effect of tDCS on post-stroke depression and using left DLPFC as stimulation site rather than as used in previous studies for treating depressive symptoms. However, questions still remain unanswered regarding the optimal stimulation parameters, positioning of electrodes, and the possible in- 
fluence of add-on medications. Moreover, the clinical profile of post-stroke depressed patients showing favorable responses to tDCS require clarification.

\section{Conclusion}

The current study showed that active tDCS to the DLPFC resulted in significant improvement of depressive symptoms, cognition, quality of life, social relationships, functional mobility and upper extremity function in post-stroke depression patients. Although further investigation is needed, the currently evidence supports the hypothesis that tDCS may constitute an effective treatment for depressive symptoms that bypasses the risks associated with antidepressants exposure, thus, tDCS may be a promising tool for treating post-stroke depressed patients.

\section{Conflicts of Interest}

The authors declare no conflicts of interest regarding the publication of this paper.

\section{References}

[1] Benjamin, E.J., Blaha, M.J., Chiuve, S.E., Cushman, M., Das, S.R., Deo, R., de Ferranti, S.D., Floyd, J., Fornage, M., Gillespie, C. and Isasi, C.R. (2017) Heart Disease and Stroke Statistics-2017 Update: A Report from the American Heart Association. Circulation, 135, e146-e603. https://doi.org/10.1161/CIR.0000000000000485

[2] Hadidi, N., Treat-Jacobson, D.J. and Lindquist, R. (2009) Poststroke Depression and Functional Outcome: A Critical Review of Literature. Heart Lung, 38, 151-162. https://doi.org/10.1016/j.hrtlng.2008.05.002

[3] Mohammed, G.F., Azab, H.M., Sayed, M.A., Elnady, H.M., Youssif, H. and Mahmoud, O.A. (2019) Risk Factors for Post-Stroke Depression in Sohag University Hospital. The Egyptian Journal of Neurology, Psychiatry and Neurosurgery, 55, 11. https://doi.org/10.1186/s41983-019-0057-z

[4] Jorge, R.E., Robinson, R.G., Tateno, A., et al. (2004) Repetitive Transcranial Magnetic Stimulation as Treatment of Post Stroke Depression: A Preliminary Study. Biological Psychiatry, 55, 398-405. https://doi.org/10.1016/j.biopsych.2003.08.017

[5] Van Asseldonk, E.H. and Boonstra, T.A. (2016) Transcranial Direct Current Stimulation of the Leg Motor Cortex Enhances Coordinated Motor Output during Walking with a Large Inter-Individual Variability. Brain Stimulation, 9, 182-190. https://doi.org/10.1016/j.brs.2015.10.001

[6] Miniussi, C. (2016) A Foreword on the Use of Noninvasive Brain Stimulation in Psychology. European Psychologist, 21, 1-3. https://doi.org/10.1027/1016-9040/a000253

[7] Nitsche, M.A., Cohen, L.G., Wassermann, E.M., Priori, A., Lang, N., Antal, A. and Pascual-Leone, A. (2008) Transcranial Direct Current Stimulation: State of the Art. Brain Stimulation, 1, 206-223. https://doi.org/10.1016/j.brs.2008.06.004

[8] Stagg, C.J. and Nitsche, M.A. (2011) Physiological Basis of Transcranial Direct Current Stimulation. The Neuroscientist, 17, 37-53. https://doi.org/10.1177/1073858410386614

[9] Martin, D.M., Moffa, A., Nikolin, S., Bennabi, D., Brunoni, A.R., Flannery, W., et al. 
(2018) Cognitive Effects of Transcranial Direct Current Stimulation Treatment in Patients with Major Depressive Disorder: An Individual Patient Data Meta-Analysis of Randomized, Sham-Controlled Trials. Neuroscience and Biobehavioral Reviews, 90, 137-145. https://doi.org/10.1016/j.neubiorev.2018.04.008

[10] Moffa, A.H., Brunoni, A.R., Fregni, F., Palm, U., Padberg, F., Blumberger, D.M., et al. (2017) Safety and Acceptability of Transcranial Direct Current Stimulation for the Acute Treatment of Major Depressive Episodes: Analysis of Individual Patient Data. Journal of Affective Disorders, 221, 1-5.

https://doi.org/10.1016/j.jad.2017.06.021

[11] Grajny, K., Pyata, H., Spiegel, K., Lacey, E.H., Xing, S., Brophy, C. and Turkeltaub, P.E. (2016) Depression Symptoms in Chronic Left Hemisphere Stroke Are Related to Dorsolateral Prefrontal Cortex Damage. The Journal of Neuropsychiatry and Clinical Neurosciences, 28, 292-298.

https://doi.org/10.1176/appi.neuropsych.16010004

[12] Hosseinzadeh, S.A., Mazhari, S., Najafi, K., Ahmadi, M., Aghaei, I. and Khaksarian, M. (2018) Anodal Transcranial Direct Current Stimulation Enhances Positive Changes in Movement Functions, Visual Attention and Depression of Patients with Chronic Ischemic Stroke: A Clinical Trail. Biomedical Research and Therapy, 5, 2841-2849. https://doi.org/10.15419/bmrat.v5i11.503

[13] Fregni, F., Boggio, P.S., Nitsche, M.A., Marcolin, M.A., Rigonatti, S.P. and Pascual-Leone, A. (2006) Treatment of Major Depression with Transcranial Direct Current Stimulation. Bipolar Disorder, 8, 203-204. https://doi.org/10.1111/j.1399-5618.2006.00291.x

[14] Rigonatti, S.P., Boggio, P.S., Myczkowski, M.L., Otta, E., Fiquer, J.T., Ribeiro, R.B., Nitsche, M.A., Pascual-Leone, A. and Fregni, F. (2008) Transcranial Direct Stimulation and Fluoxetine for the Treatment of Depression. European Psychiatry, 23, 74-76. https://doi.org/10.1016/j.eurpsy.2007.09.006

[15] Valiengo, L.C.L., Goulart, A.C., de Oliveira, J.F., Benseñor, I.M., Lotufo, P.A. and Brunoni, A.R. (2017) Transcranial Direct Current Stimulation for the Treatment of Post-Stroke Depression: Results from a Randomised, Sham-Controlled, DoubleBlinded Trial. Journal of Neurology, Neurosurgery, and Psychiatry, 88, 170-175. https://doi.org/10.1136/jnnp-2016-314075

[16] Brunoni, A.R., Nitsche, M.A., Bolognini, N., Bikson, M., Wagner, T., Merabet, L. and Ferrucci, R. (2012) Clinical Research with Transcranial Direct Current Stimulation (tDCS): Challenges and Future Directions. Brain Stimulation, 5, 175-195. https://doi.org/10.1016/j.brs.2011.03.002

[17] Hatano, S. (1976) Experience from a Multicentre Stroke Register: A Preliminary Report. Bulletin of the World Health Organization, 54, 541-553.

[18] American Psychiatric Association (2013) Diagnostic and Statistical Manual of Mental Disorders. 5th Edition, American Psychiatric Press, Inc., Washington DC. https://doi.org/10.1176/appi.books.9780890425596

[19] Folstein, M.F., Folstein, S.E. and McHugh, P.R. (1975) “Mini-Mental State": A Practical Method for Grading the Cognitive State of Patients for the Clinician. Journal of Psychiatric Research, 12, 189-198. https://doi.org/10.1016/0022-3956(75)90026-6

[20] Rossi, S., Hallett, M., Rossini, P.M. and Pascual-Leone, A. (2009) Safety, Ethical Considerations, and Application Guidelines for the Use of Transcranial Magnetic Stimulation in Clinical Practice and Research. Clinical Neurophysiology, 120, 2008-2039. https://doi.org/10.1016/j.clinph.2009.08.016

[21] Bueno, V.F., Brunoni, A.R., Boggio, P.S., et al. (2011) Mood and Cognitive Effects of 
Transcranial Direct Current Stimulation in Post-Stroke Depression. Neurocase, 17, 318-322. https://doi.org/10.1080/13554794.2010.509319

[22] Hamilton, M. (1960) A Rating Scale for Depression. Journal of Neurology, Neurosurgery, and Psychiatry, 23, 56-62. https://doi.org/10.1136/jnnp.23.1.56

[23] Williams, L.S., Weinberger, M., Harris, L.E., Clark, D.O. and Biller, J. (1999) Development of a Stroke-Specific Quality of Life Scale. Stroke, 30, 1362-1369. https://doi.org/10.1161/01.STR.30.7.1362

[24] Duan, X., Yao, G., Liu, Z., Cui, R. and Yang, W. (2018) Mechanisms of Transcranial Magnetic Stimulation Treating on Post-Stroke Depression. Frontiers in Human Neuroscience, 12, 215. https://doi.org/10.3389/fnhum.2018.00215

[25] Herrera-Melendez, A., Bajbouj, M. and Aust, S. (2019) Application of Transcranial Direct Current Stimulation in Psychiatry. Neuropsychobiology, 1-12. https://doi.org/10.1159/000501227

[26] Valiengo, L., Casati, R., Bolognini, N., Lotufo, P.A., Benseñor, I.M., Goulart, A.C. and Brunoni, A.R. (2016) Transcranial Direct Current Stimulation for the Treatment of Post-Stroke Depression in Aphasic Patients: A Case Series. Neurocase, 22, 225-228. https://doi.org/10.1080/13554794.2015.1130231

[27] Grimm, S., Beck, J., Schuepbach, D., Hell, D., Boesiger, P., Bermpohl, F., et al. (2008) Imbalance between Left and Right Dorsolateral Prefrontal Cortex in Major Depression Is Linked to Negative Emotional Judgment: An fMRI Study in Severe Major Depressive Disorder. Biological Psychiatry, 63, 369-376. https://doi.org/10.1016/j.biopsych.2007.05.033

[28] Moliadze, V., Antal, A. and Paulus, W. (2010) Electrode-Distance Dependent After-Effects of Transcranial Direct and Random Noise Stimulation with Extracephalic Reference Electrodes. Clinical Neurophysiology, 121, 2165-2171. https://doi.org/10.1016/j.clinph.2010.04.033

[29] Viana, R.T., Laurentino, G.E., Souza, R.J., et al. (2014) Effects of the Addition of Transcranial Direct Current Stimulation to Virtual Reality Therapy after Stroke: A Pilot Randomized Controlled Trial. NeuroRehabilitation, 34, 437-446. https://doi.org/10.3233/NRE-141065

[30] Elsner, B., Kwakkel, G., Kugler, J. and Mehrholz, J. (2017) Transcranial Direct Current Stimulation (tDCS) for Improving Capacity in Activities and Arm Function after Stroke: A Network Meta-Analysis of Randomized Controlled Trials. Journal of NeuroEngineering and Rehabilitation, 14, 95. https://doi.org/10.1186/s12984-017-0301-7

[31] Elsner, B., Kugler, J. and Mehrholz, J. (2018) Transcranial Direct Current Stimulation (tDCS) for Upper Limb Rehabilitation after Stroke: Future Directions. Journal of NeuroEngineering and Rehabilitation, 15, 106. https://doi.org/10.1186/s12984-018-0459-7

[32] Schjetnan, A.G., Faraji, J., Metz, G.A., Tatsuno, M. and Luczak, A. (2013) Transcranial Direct Current Stimulation in Stroke Rehabilitation: A Review of Recent Advancements. Stroke Research and Treatment, 2013, Article ID: 170256. https://doi.org/10.1155/2013/170256

[33] Fregni, F., Boggio, P., Nitsche, M. and Rigonatti, S. (2006) Cognitive Effects of Repeated Sessions of Transcranial Direct Current Stimulation in Patients with Depression. Depression and Anxiety, 23, 482-484. https://doi.org/10.1002/da.20201

[34] Pisoni, A., Mattavelli, G., Papagno, C., Rosanova, M., Cacali, A. and Lauro, L. (2018) Cognitive Enhancement Induced by Anodal tDCS Drives Circuit-Specific Cortical Plasticity. Cerebral Cortex, 28, 1132-1140.

https://doi.org/10.1093/cercor/bhx021 